\title{
CX3CL1 increases invasiveness and metastasis by promoting epithelial-to-mesenchymal transition through the TACE/TGF- $\alpha$ /EGFR pathway in hypoxic androgen-independent prostate cancer cells
}

\author{
JIEBING TANG ${ }^{1,3^{*}}$, LIJIE XIAO ${ }^{1,2^{*}}$, RONGJUN CUI ${ }^{1,5}$, DONG LI $^{1}$, XIULAN ZHENG $^{4}$, \\ LIJUAN ZHU ${ }^{1}$, HUI SUN ${ }^{1}$, YUJIA PAN ${ }^{1}$, YANDAN DU ${ }^{1}$ and XIAOGUANG YU ${ }^{1}$

\begin{abstract}
${ }^{1}$ Department of Biochemistry and Molecular Biology, Harbin Medical University, Harbin, Heilongjiang 150081; Departments of ${ }^{3}$ Gastrointestinal Medical Oncology and ${ }^{4}$ Ultrasonography, The Affiliated Tumor Hospital of Harbin Medical University, Harbin, Heilongjiang 150081; ${ }^{5}$ Department of Biochemistry and Molecular Biology, Mudanjiang Medical University, Mudanjiang, Heilongjiang 157011, P.R. China
\end{abstract} \\ ${ }^{2}$ College of Life Science and Technology, Heilongjiang Bayi Agricultural University, Daqing, Heilongjiang 163319;
}

Received August 20, 2015; Accepted November 6, 2015

DOI: $10.3892 /$ or.2015.4470

\begin{abstract}
Epithelial-to-mesenchymal transition (EMT) endows cancer cells with enhanced invasive and metastatic potential during cancer progression. Fractalkine, also known as chemokine (C-X3-C motif) ligand 1 (CX3CL1), the only member recognized so far that belongs to the $\mathrm{CX} 3 \mathrm{C}$ chemokine subfamily, was reported to participate in the molecular events that regulate cell adhesion, migration and survival of human prostate cancer cells. However, the relationship between CX3CL1 and EMT remains unknown. We treated DU145 and PC-3 cells with CX3CL1 under hypoxic conditions. The migration and invasion abilities of DU145 and PC-3 cells were detected by Transwell assays. Induction of EMT was verified by morphological changes in the DU145 and PC-3 cells and analysis of protein expression of EMT markers such as E-cadherin and vimentin. To identify the involved signaling pathway in CX3CL1-induced EMT, activation of epidermal growth factor receptor (EGFR) was measured using western blot analysis, and Slug expression was detected with or without an EGFR inhibitor prior to CX3CL1 treatment. Concentrations of soluble and total TGF- $\alpha$ in the CX3CL-treated DU145 cells were detected by
\end{abstract}

Correspondence to: $\mathrm{Dr}$ Xiaoguang $\mathrm{Yu}$, Department of Biochemistry and Molecular Biology, Harbin Medical University, Harbin, Heilongjiang 150081, P.R. China

E-mail: xiaoguang_yu@hotmail.com

${ }^{*}$ Contributed equally

Key words: CX3CL1, prostate cancer, EGFR, TGF- $\alpha$, metastasis, epithelial-to-mesenchymal transition
ELISA. Additionally, we determined the involvement of the TACE/TGF- $\alpha /$ EGFR pathway in CX3CL1-induced EMT using RNA interference and specific inhibitors. CX3CL1 increased the migration and invasiveness of the DU145 and PC-3 cells, and resulted in characteristic alterations of EMT. Our results demonstrated that TACE/TGF- $\alpha /$ EGFR pathway activation and subsequent upregulation of Slug expression were responsible for CX3CL1-induced EMT, and contributed to the migration and invasion of prostate cancer cells. Inhibition of TACE/TGF- $\alpha /$ EGFR signaling reversed EMT and led to reduced migration and invasion abilities of the prostate cancer cells. We provide initial evidence that CX3CL1 exposure resulted in EMT occurrence and enhancement of cell migration and invasion through a mechanism involving activation of TACE/TGF- $\alpha /$ EGFR signaling. These findings revealed that CX3CL1 may serve as a new target for the treatment of prostate cancer.

\section{Introduction}

In Western countries, prostate cancer has surpassed lung cancer as the most prevalent cancer and has become the second leading cause of cancer-related deaths among men (1). Distant metastasis is the primary cause of death for the majority of prostate cancer patients. Early-stage prostate cancer depends upon androgens. However, $70-80 \%$ of patients with metastatic disease respond initially to androgen-deprivation therapy (ADT), yet the tumors may become hormone-refractory and lethal due to metastatic spread several years after initial treatment with anti-androgens (2). Although microtubule-targeting agents, such as docetaxel, improve the overall survival of patients with distant disease by 2-3 months, tumor resistance eventually occurs (3). In addition, several targeted therapies involved in clinical trials have shown little effect on prolonging survival. Therefore, new agents for the treatment of androgenresistant prostate cancer are needed. 
Metastasis is a complex process whereby tumor cells penetrate the basement membranes of blood vessels, survive in the blood stream until extravasating to secondary sites, and form metastases (4). This process requires epithelial-to-mesenchymal transition (EMT). During EMT, tumor cells lose epithelial polarity and adopt a spindle-shaped morphology and migratory fibroblastoid phenotype. These transitions endow cancer cells with enhanced invasive and metastatic potential (5). EMT involves multiple signaling pathways, and is regulated by a set of transcription factors, including Snail, Slug and Twist, which lead to loss of cell-cell adhesion molecules such as E-cadherin and gain of mesenchymal proteins such as vimentin $(6,7)$. Importantly, these transcription factors as key regulators of EMT have been confirmed to be critical to metastasis and the invasive ability of cancer cells in prostate cancer progression $(8,9)$. Furthermore, loss of E-cadherin expression was found in high-grade prostate cancer and is associated with a reduction in survival $(10,11)$. Therefore, clarifying the initial molecular mechanisms regulating the EMT phenotype allows the development of novel therapeutic strategies for the prevention and treatment of prostate cancer.

Recent findings have suggested that a wide variety of molecules promote EMT, such as chemokines (12). Chemokines are small cytokine-like secreted proteins with selective chemoattractant properties and have emerged as important molecular regulators in cancer biology. Growing evidence has demonstrated that various chemokines promote tumor growth and metastasis via mediating EMT (13). Fractalkine also known as chemokine (C-X3-C motif) ligand 1 (CX3CL1) is the only described member of the CX3C family. Recent studies have confirmed that CX3XL1 is highly expressed in various cancers, and is involved in tumor spread and organ-specific metastases (14-16). In prostate cancer, the CX3CL1/CX3CR1 axis activates the PI3K/AKT survival pathway and plays a crucial role in skeletal metastasis (17). Our previous study showed that hypoxia exposure upregulated CX3CR1 expression via HIF and the NF- $\kappa \mathrm{B}$ pathway in androgen-independent prostate cancer cells (18). Although there has been increasing interest in the role of CX3CL1/CX3CR1 during tumor metastasis, little is known concerning the detailed mechanisms involved.

Hypoxia, a well-recognized microenvironmental factor in prostate cancer development, is closely related with cancer relapse, metastases and resistance to chemotherapy (19). Futhermore, hypoxia has been implicated in the promotion of the EMT process by activating a multitude of molecular signaling pathways that drive EMT (20). The present study focused on whether CX3CL1/CX3CR regulate EMT and promote tumor migration and invasion in androgen-independent prostate cancer cells under hypoxic condition, and explored the potential molecular mechanisms involved.

\section{Materials and methods}

Reagents and antibodies. Recombinant human fractalkine (CX3CL1) and TGF- $\alpha$ were purchased from PeproTech (Rocky Hill, NJ, USA). EGFR inhibitor AG1478 was obtained from Cell Signaling Technology (Beverly, MA, USA).

Primary antibodies against E-cadherin (cat. \#3195), vimentin (cat. \#5741) and slug (cat.\#9585) were purchased from
Cell Signaling Technology (Danvers, MA, USA). Antibodies for EGFR (cat.\# sc-03), phosphor-EGFR (cat.\# sc-101668, Tyr1173) and $\beta$-actin (cat.\# sc-47778) were purchased from Santa Cruz Biotechnology (Santa Cruz, CA, USA). TGF- $\alpha$ neutralizing antibody (cat.\# sc-9043) was from Calbiochem (La Jolla, CA, USA).

Cell culture and hypoxia treatment. Human prostate cancer cell lines DU145 and PC-3 were purchased from the American Type Culture Collection (ATCC; Manassas, VA, USA). Cells were cultrued in RPMI-1640 medium containing 10\% fetal bovine serum (FBS; Gibco-BRL, Grand Island, NY, USA) and $1 \mathrm{X}$ penicillin/streptomycin (Invitrogen, Carlsbad, CA, USA) at $37^{\circ} \mathrm{C}$ in a humidified atmosphere (5\% $\mathrm{CO}_{2} / 95 \%$ air). For hypoxia treatment, the cells were incubated in a hypoxic chamber (Thermo Scientific) maintained at $1 \% \mathrm{O}_{2}, 5 \% \mathrm{CO}_{2}$ and $94 \% \mathrm{~N}_{2}$ at $37^{\circ} \mathrm{C}$ for $24-48 \mathrm{~h}$.

Matrigel invasion and migration assays. The cell invasion assay was performed using Matrigel-coated 24-well Transwell inserts containing polycarbonate filters with $8-\mu \mathrm{m}$ pores (BD Biosciences) according to a previously published protocol. Briefly, $5 \times 10^{4}$ cells in $200 \mu 1$ of serum-free RPMI-1640 medium were seeded onto the upper chambers, whereas basal serum-free medium or medium with recombinant human CX3CL1 $(200 \mathrm{ng} / \mathrm{ml})$, TGF- $\alpha(50 \mu \mathrm{g} / \mathrm{ml})$ or Ab-TGF- $\alpha$ $(10 \mu \mathrm{g} / \mathrm{ml})$ was added into the bottom chamber. After the assay chambers were incubated for 24 or $48 \mathrm{~h}$ under hypoxic conditions, the non-invading cells on the upper surface of the membrane were carefully removed with a cotton swab, and the filter membrane was fixed with cool methanol for $15 \mathrm{~min}$, subsequently stained with $0.1 \%$ crystal violet for $30 \mathrm{~min}$. Invading cells on the lower surface of the membrane were examined and counted under a microscope (Olympus IX51; Olympus, Japan) at a magnification of x200. Five random fields were numerically averaged and counted for each assay. Cell migration assay was performed with a similar procedure without Matrigel coating. All experiments were performed in triplicate and repeated three times.

ELISA assay. An equal number of cells were plated and cultured for the indicated times in RPMI-1640 medium supplemented with $10 \%$ FBS. The supernatant was collected and TGF- $\alpha$ levels were determined using a commercial human TGF- $\alpha$ ELISA kit (Oncogene, Boston, MA, USA) according to the manufacturer's instructions.

Western blot analysis. Western blot analysis was carried out as described previously (18). Briefly, cells were harvested, washed, and lysed in ice cold lysis buffer containing a mixture of protease inhibitors and phosphatase inhibitor. After centrifuged at $12,000 \mathrm{x}$ g for $30 \mathrm{~min}$, the supernatant was collected and the protein concentration in the extracts was determined using BCA reagent (Beyotime Institute of Biotechnology, Nanjing, China) according to the manufacturer's protocols. Equal amounts of proteins (40 $\mu \mathrm{g})$ were loaded, fractionated by $12 \%$ SDS-PAGE and transferred onto nitrocellulose membranes. After being blocked with $5 \%$ non-fat milk in TBST for $2 \mathrm{~h}$ at room temperature, the membranes were incubated with primary antibodies for E-cadherin $(1: 1,000$ 
rabbit monoclonal), vimentin (1:1,000 rabbit monoclonal), Slug (1:1,000 rabbit monoclonal) , EGFR (1:500 rabbit monoclonal), p-EGFR (1:300 rabbit monoclonal) and $\beta$-actin (1:1,000 rabbit monoclonal) at $4{ }^{\circ} \mathrm{C}$ overnight. The bound primary antibody was detected by incubating with appropriate horseradish peroxidase-conjugated secondary antibodies at a dilution of 1:2,000 in TBST for $2 \mathrm{~h}$. The expression levels of $\beta$-actin were monitored as an internal control for the semi-quantitative PCR. Immunoreactive bands were visualized using the western blot analysis Super ECL Plus detection reagents (Applygen Technologies Inc., Beijing, China) and analyzed by Quantity One software.

RNA interference. For the small interfering RNA (siRNA) treatment, oligonucleotides corresponding to nucleotide sequences of Slug and ADAM17 were synthesized commercially by Invitrogen (Life-Technologies). The siRNA sequences were as follows: Slug siRNA 1, 5'-AUGAGUUGUAACCAG GUCAGCUUCC-3'; Slug siRNA 2, 5'-AUACAUGACAUAU UUCCCUCCCUGG-3'; Slug siRNA 3, 5'-UUUCUUUGCU GUCAACACGAUUCUG-3'; and ADAM17 siRNA, 5'-CAGA AUCGUGUUGACAGCAAAGAAA-3'. Cells were transfected at 40-60\% confluency with siRNA specific for Slug, ADAM17 or a scrambled sequence at the concentration of $100 \mathrm{nM}$ using Lipofectamine 2000 transfection reagent (Invitrogen) according to the manufacturer's recommendations. The transfected cells were collected at 48 or $72 \mathrm{~h}$ and efficiency of protein knockdown was assessed by western blot analysis.

Statistical analysis. Each experiment was replicated in triplicate. All data are presented as mean \pm SD. Statistical analyses were performed using Statistics Package for Social Science (SPSS 20.0 for Windows; IBM, Armonk, NY, USA). One-way ANOVA was used for multiple comparisons. A p-value $<0.05$ was considered statistically significant.

\section{Results}

CX3CL1 increases the migration and invasiveness of hypoxic androgen-independent prostate cancer cells. Initially, we examined the effect of CX3CL1 on the abilities of invasion and migration in androgen-independent prostate cancer cells. Two types of androgen-independent prostate cancer cell lines DU145 and PC-3 were treated with CX3CL1 at various concentrations $(0-400 \mathrm{ng} / \mathrm{ml})$ for a period of $48 \mathrm{~h}$ under hypoxic conditions. Transwell assays showed that the ability of DU145 and PC-3 cells to cross the basement membrane matrix following treatment with CX3CL1 at a concentration of 200 or $300 \mathrm{ng} / \mathrm{ml}$ was markedly increased compared to the untreated cells. DU145 cells exhibited more aggressive and invasive activity than PC-3 cells responding to CX3CL1 stimulation (Fig. 1).

CX3CL1 induces a mesenchymal phenotype in hypoxic androgen-independent prostate cancer cells. EMT is a major process leading to increased migration and invasive abilities in cancer cells. To investigate whether the enhancement of migration and invasive abilities in androgen-independent prostate cancer cells resulted from the EMT process, we observed morphological changes of DU145 and PC-3 cells
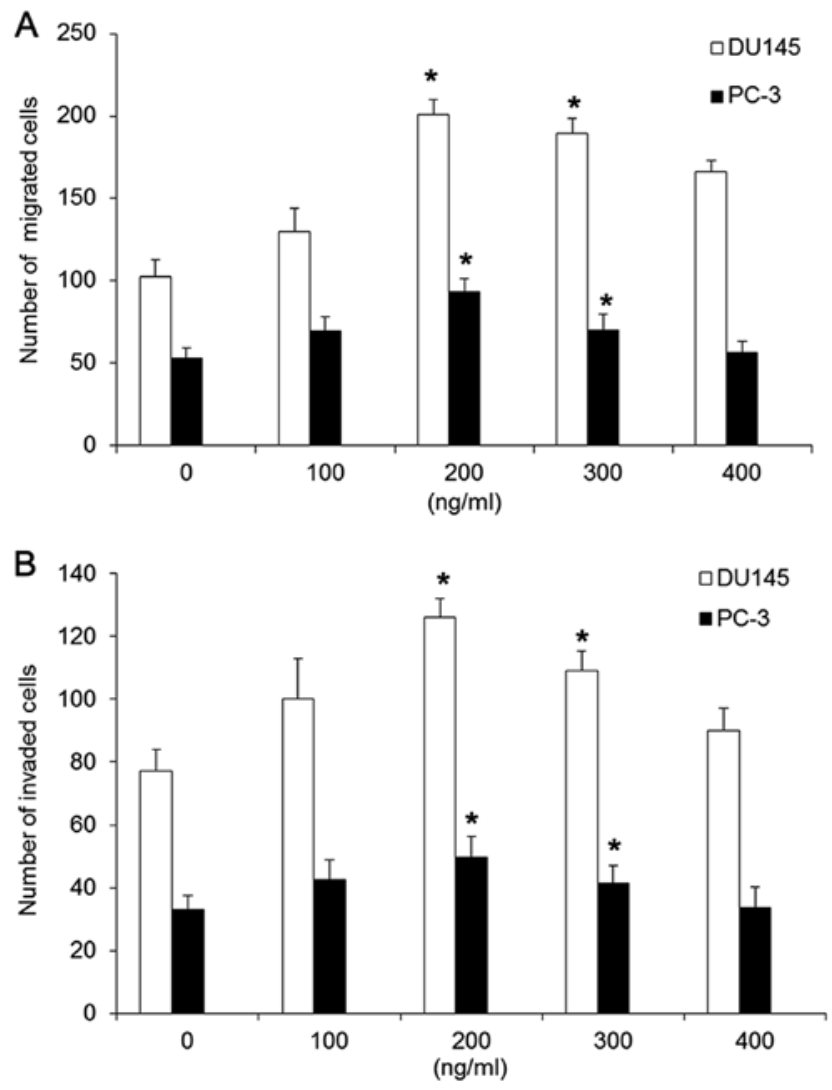

Figure 1. Effect of CX3CL1 on the migration and invasiveness of DU145 and PC-3 cells. (A) Transwell migration assays. DU145 and PC-3 cells were seeded onto the upper chamber of Transwell, and basal serum-free medium or medium with different concentrations of recombinant human CX3CL1 was added into the bottom chamber. The cells were then incubated under hypoxic conditions for $48 \mathrm{~h}$. The number of migrated cells was counted. (B) Transwell invasion assays. Data are presented as means \pm SD from three independent experiments. ${ }^{*}$ p $<0.05$ vs. the untreated group.

following treatment with CX3CL1 at various concentrations $(0-300 \mathrm{ng} / \mathrm{ml})$ for a period of $48 \mathrm{~h}$ under hypoxic conditions. As shown in Fig. 2A, most treated cells not only exhibited an fibroblastic and elongated morphology but also showed occasional misorientation and a loose association compared to the closely contacted monolayer, polygon cobblestone-like cells. An accompanying alteration in expression of epithelial and mesenchymal markers is often used to identify cells which are undergoing EMT. Western blot analysis showed that there was decreased expression of E-cadherin but elevated expression of vimentin in the DU145 and PC-3 cells upon CXCL3 stimulation at a concentration of 200 or $300 \mathrm{ng} / \mathrm{ml}$ for $48 \mathrm{~h}$ (Fig. 2B and C). Taken together, we provided strong evidence that CXCL3 induced an EMT-like phenotype in the androgen-independent prostate cancer cells.

EGFR-dependent Slug pathway is implicated in CX3CL1-induced EMT. Epidermal growth factor receptor (EGFR), an erbB-family receptor tyrosine kinase, is constitutively active in a variety of tumors and overexpressed in $~ 30 \%$ of prostate cancer cases (21). Experimental and preclinical evidence showed that EGFR overexpression is correlated with prostate cancer aggressiveness (22). Thus, to identify 


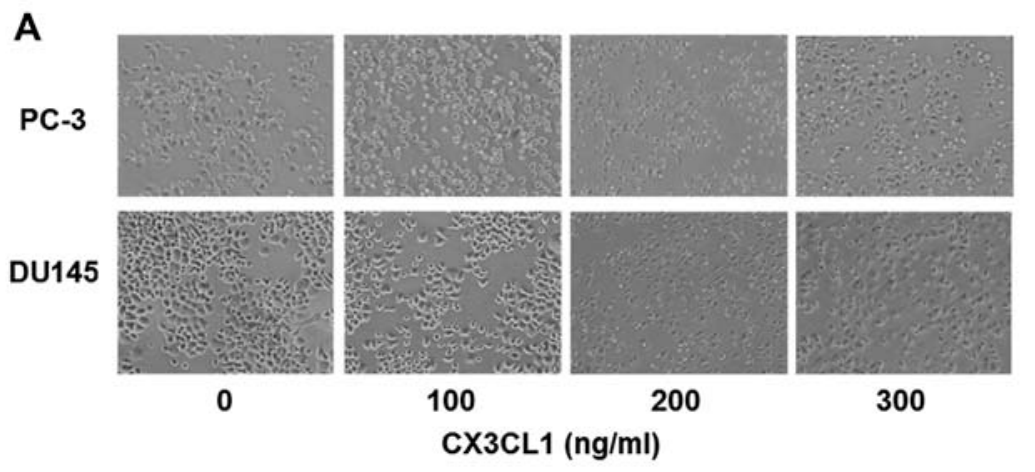

B

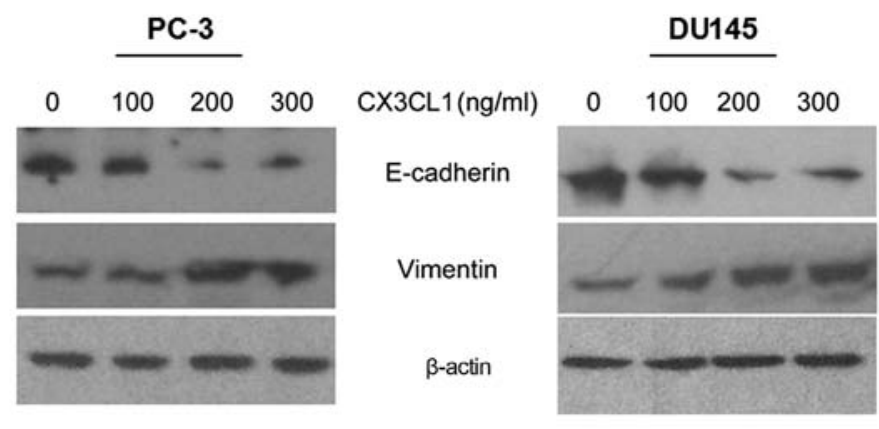

C
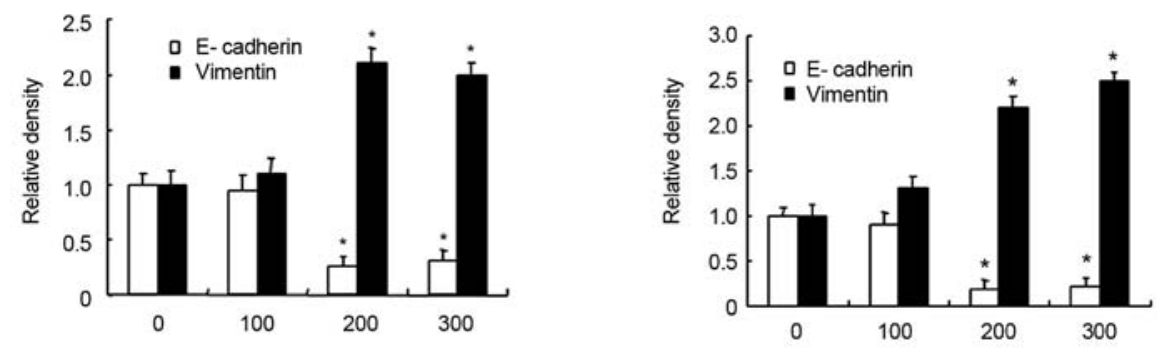

Figure 2. CX3CL1 induces a mesenchymal phenotype in DU145 and PC-3 cells. DU145 and PC-3 cells were treated with CX3CL1 at various concentrations $(0-300 \mathrm{ng} / \mathrm{ml})$ for a period of $48 \mathrm{~h}$ under hypoxic conditions. (A) Microscopic observations of cell morphological changes of EMT (original magnification, x200). (B) Expression of EMT markers at the protein level was measured by western blot analysis. $\beta$-actin was used as an internal control. (C) Statistical analyses of protein results from B. Data are presented as the means \pm SD from three independent experiments. " $p<0.05$ vs. untreated group.

whether EGFR pathway activation exists in CX3CL-induced EMT occurrence, we determined the expression levels of total EGFR and phospho-EGFR (p-EGFR) in DU145 cells treated with $200 \mathrm{ng} / \mathrm{ml}$ of CX3CL1. Western blot analysis showed that p-EGFR expression was significantly elevated in the DU145 cells treated with CX3CL1 compared with the untreated cells (Fig. 3A and C), indicating CX3CL1-mediated activation of the EGFR signaling pathway. Accumulating evidence suggests that the EGFR family and its downstream mediators, for instance, Slug, serving as a transcription repressor of E-cadherin, are involved in EMT (23). Our results showed that CX3CL1 markedly elevated the protein expression level of Slug in the DU145 cells, and the EGFR inhibitor AG1478 abrogated this elevation (Fig. 3B and D), suggesting that CX3CL1 regulated Slug expression in an EGFR-dependent manner.

Next, to further confirm the role of the EGFR-dependent Slug pathway in CX3CL-induced EMT, we examined the protein expression levels of EMT markers in the DU145 cells following CX3CL1 treatment alone or combined with AG1478 pretreatment. The western blot results demonstrated that CX3CL1 treatment led to a significant EMT change as indicated by E-cadherin and vimentin protein levels, whereas AG1478 pretreatment inhibited CX3CL1-induced downregulation of E-cadherin and upregulation of vimentin (Fig. 4A and C). In order to determine whether Slug is associated with the changes in the protein levels of E-cadherin and vimentin, DU145 cells were transfected with Slug-specific siRNA or non-specific siRNA, and western blotting was performed after $24 \mathrm{~h}$ of the transfections. As shown in Fig. 4B and D, Slug protein expression level was greatly reduced in the Slug-siRNA-transfected cells, compared with scrambled-siRNA transfected cells. Meanwhile, transfection with Slug-siRNA attenuated the regulatory effect of CX3CL1 on E-cadherin and vimentin protein expression, which indicated that Slug was involved in CX3CL-induced EMT. Taken together, we provided evidence that CX3CL caused EGFR pathway activation and subsequent Slug expression, which led to the EMT process.

TACE/TGF- $\alpha$ is responsible for CX3CL1-induced EGFR activation and EMT in hypoxic DU145 cells. EGFR is activated by binding of its specific ligands. TGF- $\alpha$ is one of the key ligands for EGFR. Thus, we hypothesized that CX3CL1 may activate EGFR through increased shedding of pro-TGF- $\alpha$. After CX3CL1 treatment for $20 \mathrm{~min}$, the concentrations of 
A - EGF CX3CL1
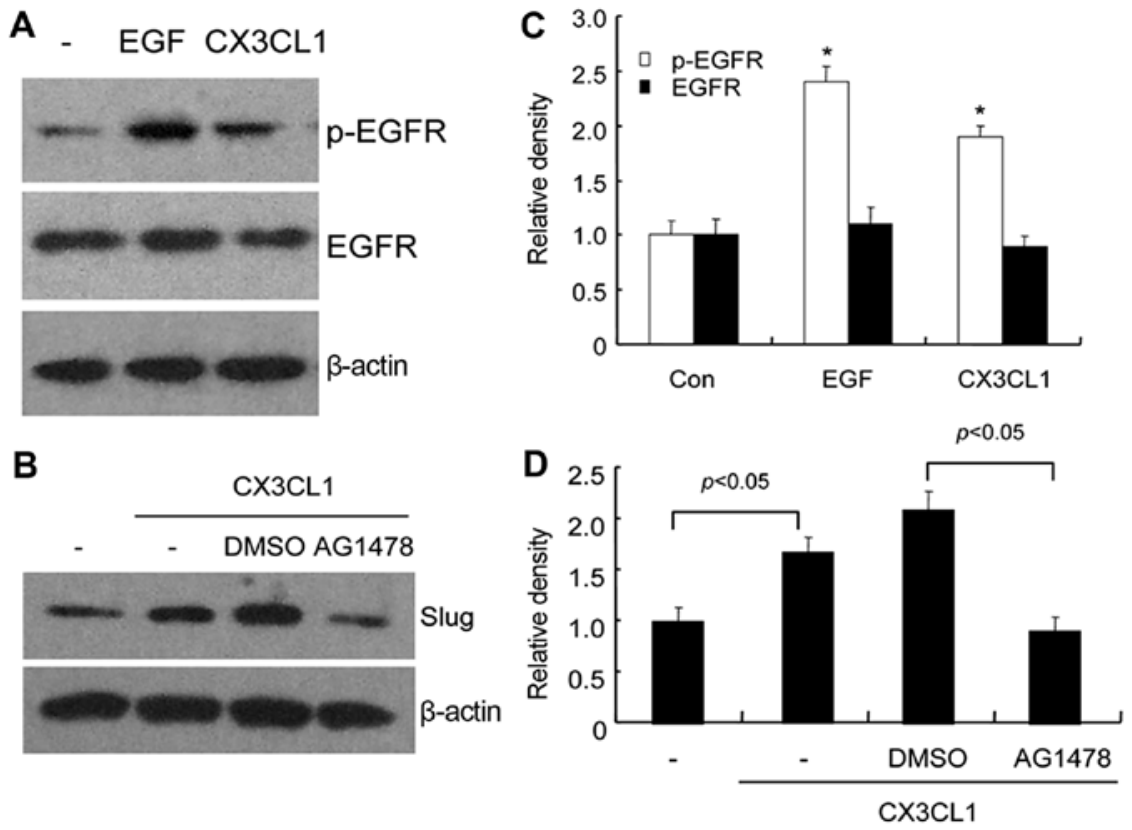

Figure 3. CX3CL1 activates the EGFR signaling pathway and upregulates Slug expression. (A) EGFR protein expression. DU145 cells treated with $200 \mathrm{ng} / \mathrm{ml}$ of CX3CL1 were exposed to $1 \% \mathrm{O}_{2}$ for $10 \mathrm{~min}$, and levels of total EGFR and p-EGFR expression were determined by western blot analysis. $\beta$-actin was used as an internal control, EGF was used as a positive control. (B) Slug protein expression. DU145 cells were pretreated with or without DMSO or AG1478 for $1 \mathrm{~h}$, followed by exposure to $200 \mathrm{ng} / \mathrm{ml}$ of CX3CL1 for $24 \mathrm{~h}$ under hypoxic condition, and then Slug expression was detected by western blot analysis. (C and D) Statistical analyses of the protein results from A and B. Data are presented as the means \pm SD from three independent experiments. "p $<0.05$ vs. control.

A
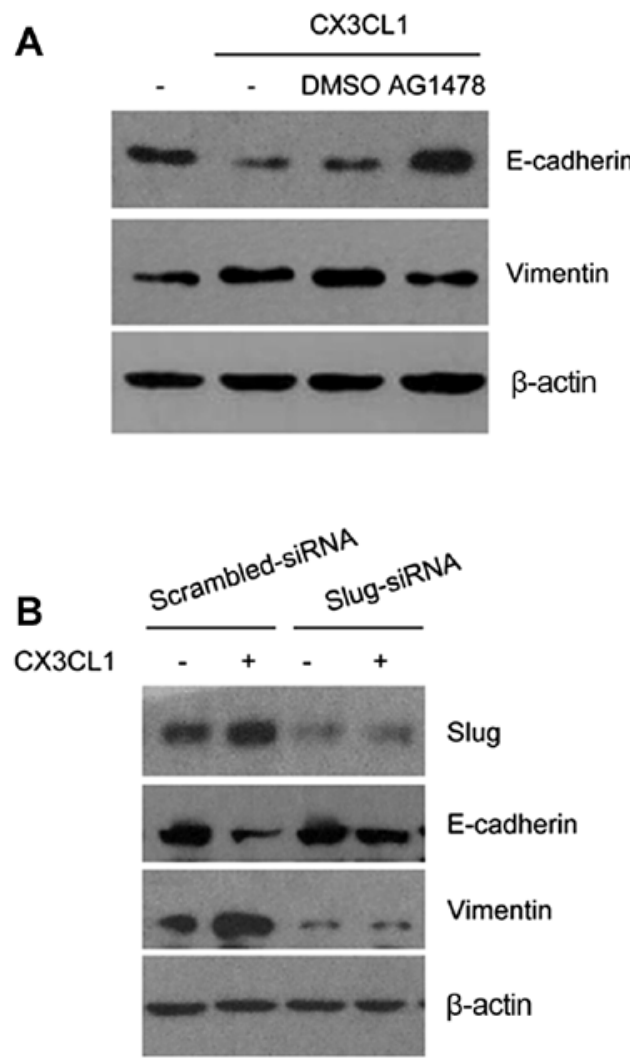
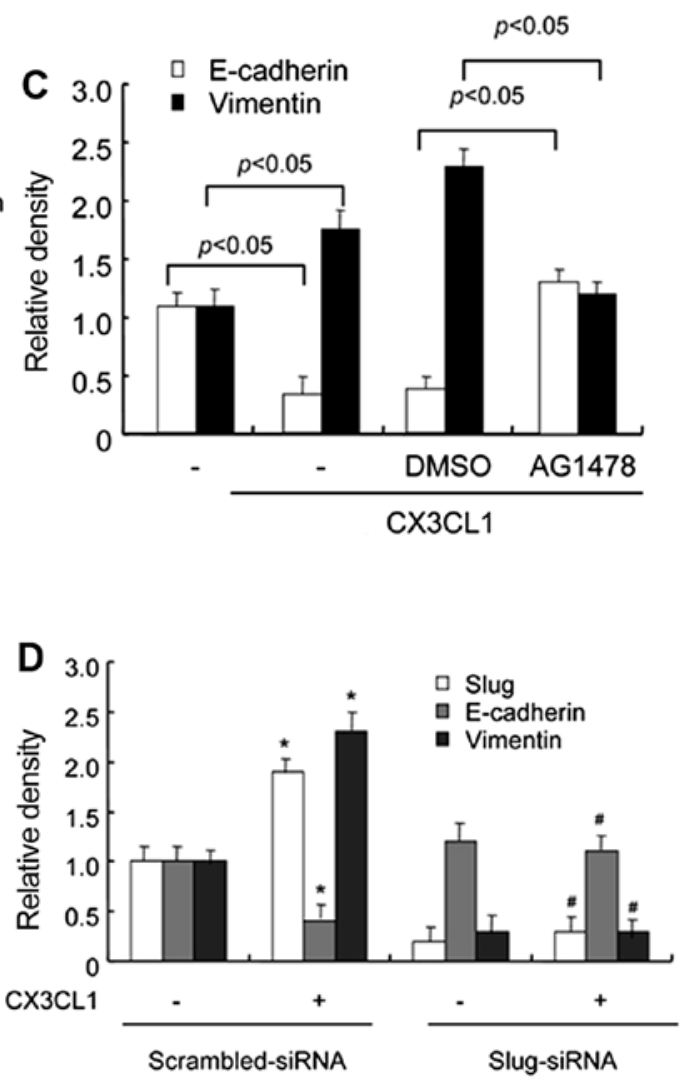

Figure 4. EGFR-dependent Slug pathway is implicated in CX3CL1-induced EMT. (A) DU145 cells were pretreated with or without DMSO or AG1478 for $1 \mathrm{~h}$, and then were exposed to $200 \mathrm{ng} / \mathrm{ml}$ of CX3CL1 for $24 \mathrm{~h}$ under hypoxic condition. Levels of E-cadherin and vimentin protein expression were detected by western blot analysis. (B) DU145 cells were transfected with Slug-siRNA or scrambled-siRNA for $72 \mathrm{~h}$, followed by exposure to $200 \mathrm{ng} / \mathrm{ml}$ of CX3CL1 for $24 \mathrm{~h}$ under hypoxic condition, and then levels of Slug, E-cadherin and vimentin protein expression were detected by western blotting. (C and D) Statistical analyses of the protein results from A and B. These experiments were conducted in triplicate. ${ }^{*} \mathrm{p}<0.05$ vs. control. ${ }^{*} \mathrm{p}<0.05$ vs. scrambled-siRNA. 
A
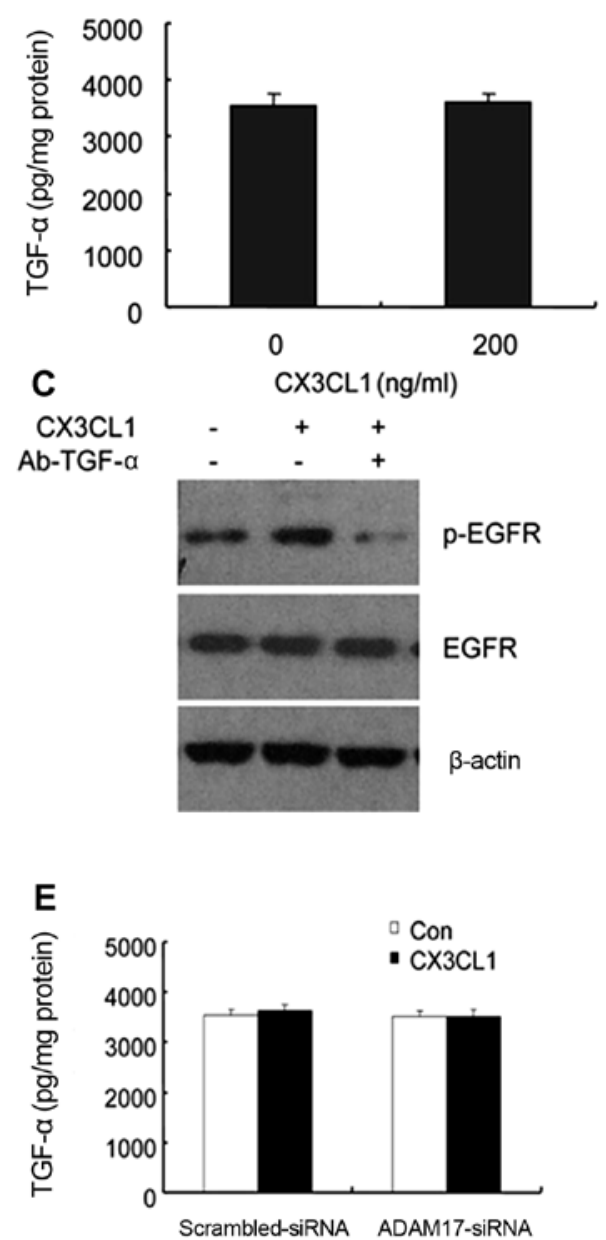

G

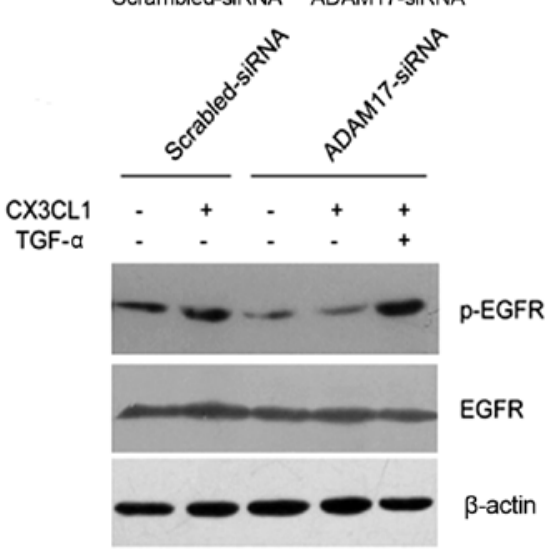

B
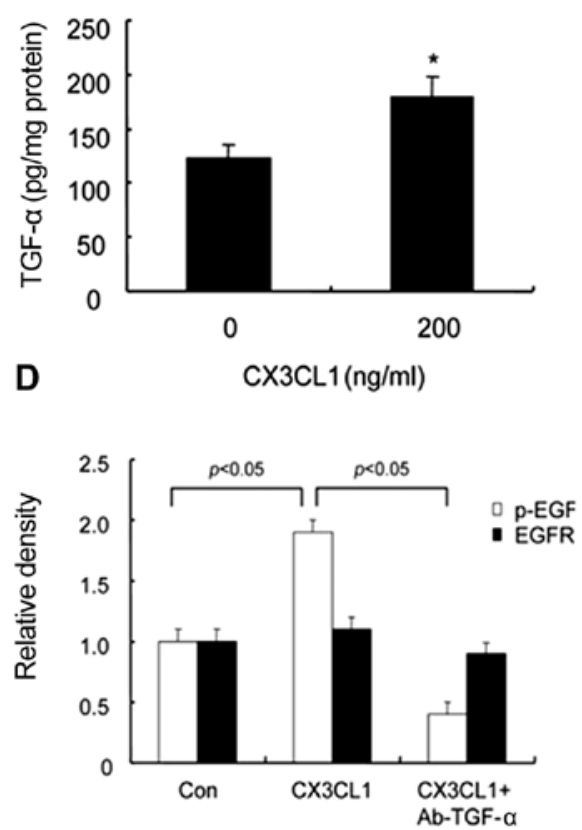

$\mathbf{F}$

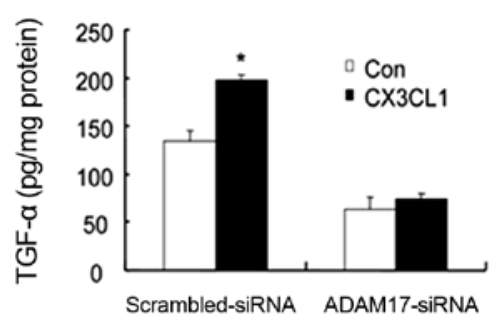

H

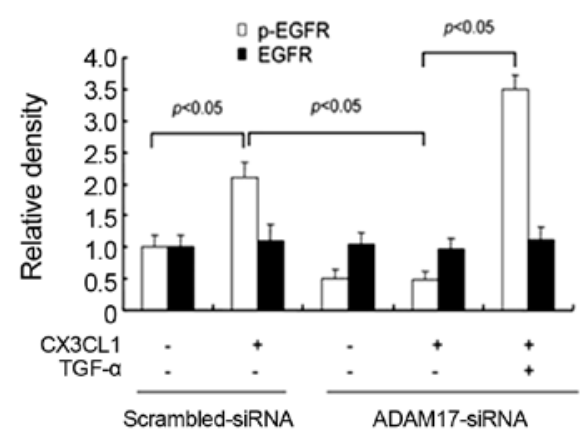

Figure 5. TACE/TGF- $\alpha$ is responsible for CX3CL1-induced EGFR activation. (A and B) DU145 cells were treated with $200 \mathrm{ng} / \mathrm{ml}$ of CX3CL1 for $20 \mathrm{~min}$ under hypoxic condition, and then the concentrations of total TGF- $\alpha$ (A) and soluble TGF- $\alpha$ (B) in culture medium were detected by ELISA. "p<0.05 vs. the control. (C) Levels of total EGFR and p-EGFR expression were determined by western blot analysis. DU145 cells were pretreated with or without Ab-TGF- $\alpha$ for $1 \mathrm{~h}$, followed by exposure to $200 \mathrm{ng} / \mathrm{ml}$ of CX3CL1 for another $10 \mathrm{~min}$. (D) Statistical analyses of the protein results from C. (E and F) Prior to treatment with CX3CL1, DU145 cells were transfected with ADAM17-siRNA or scrambled-siRNA for $48 \mathrm{~h}$. Concentrations of total TGF- $\alpha$ (E) and soluble TGF- $\alpha$ (F) in culture medium were detected by ELISA. (G) DU145 cells were pre-transfected with ADAM17-siRNA or scrambled-siRNA for $48 \mathrm{~h}$, followed by exposure to $200 \mathrm{ng} / \mathrm{ml}$ of CX3CL1 with or without $50 \mu \mathrm{g} / \mathrm{ml}$ of TGF- $\alpha$ pretreatment for $10 \mathrm{~min}$, and then levels of total EGFR and p-EGFR expression were determined by western blot analysis. (H) Statistical analyses of protein results from G. Data are presented as the means \pm SD of three independent experiments.

soluble and total TGF- $\alpha$ in culture medium were detected by ELISA. Our results demonstrated that the concentration of soluble TGF- $\alpha$ significantly increased but that of total TGF- $\alpha$ remained unchanged upon CX3CL1 stimulation (Fig. 5A and B). To further investigate the role of TGF- $\alpha$ in CX3CL-induced EGFR activation, DU145 cells were pretreated with a neutralizing antibody of TGF- $\alpha$ (Ab-TGF- $\alpha$ ) to inhibit TGF- $\alpha$ activity. The western blot analysis showed that CX3CL1-induced EGFR activation was significantly inhibited by Ab-TGF- $\alpha$ (Fig. 5C and D), indicating that TGF- $\alpha$ activity is essential to CX3CL1-induced EGFR activation in DU145 cells. 


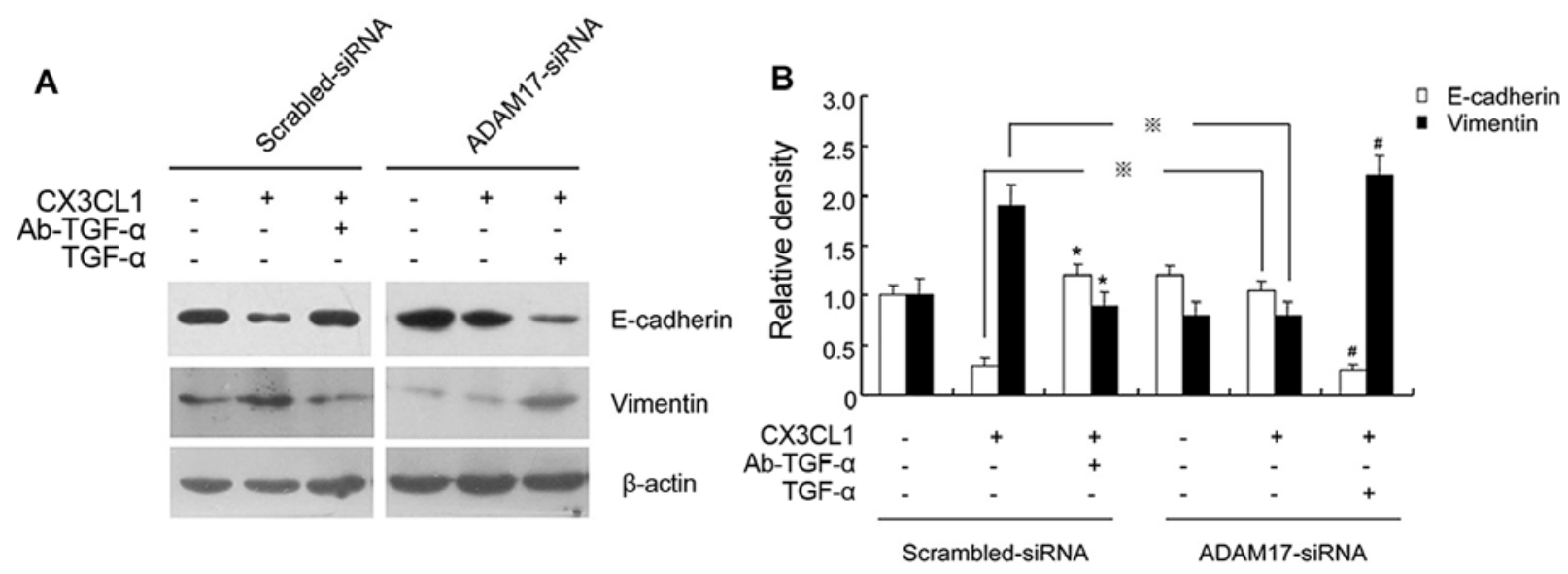

Figure 6. Involvement of the TACE/TGF- $\alpha$ signaling pathway in CX3CL1-induced EMT. (A) Expression of EMT markers at the protein level were measured by western blot analysis. DU145 cells pre-transfected with ADAM17-siRNA for $48 \mathrm{~h}$ were exposed to $200 \mathrm{ng} / \mathrm{ml}$ of CX3CL1, with or without $50 \mu \mathrm{g} / \mathrm{ml}$ of TGF- $\alpha$ or $10 \mu \mathrm{g} / \mathrm{ml}$ of Ab-TGF- $\alpha$ pretreatment under hypoxic conditions. (B) Statistical analyses of the protein results from A. These experiments were conducted in triplicate. ${ }^{*}$ p $<0.05$ vs. CX3CL1 alone. ${ }^{*}$ p $<0.05$ vs. CX3CL1 alone. "p $<0.05$ vs. scrambled-siRNA.

A

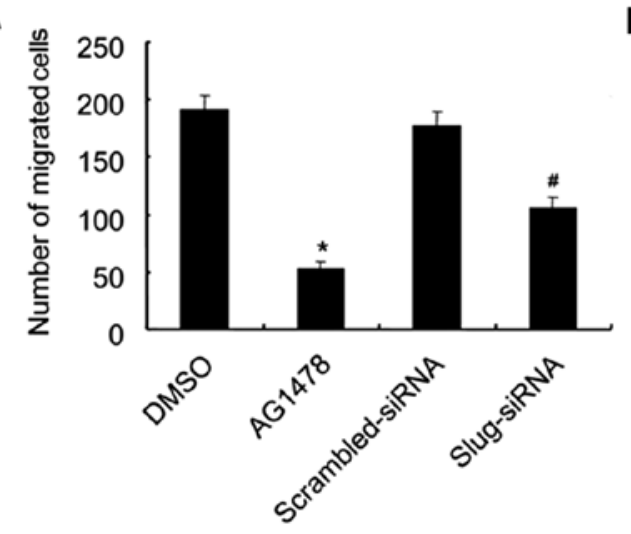

B

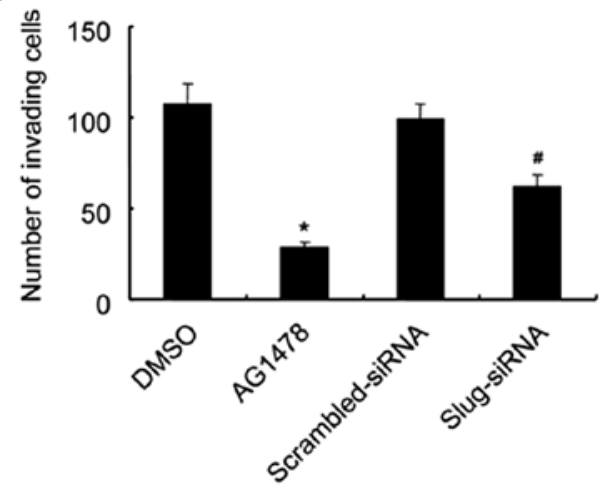

Figure 7.EGFR-dependent Slug pathway is involved in CX3CL1-induced migration and invasion of DU145 cells. DU145 cells were transfected with Slug-siRNA or scrambled-siRNA for $48 \mathrm{~h}$, pretreated with DMSO or AG1478 for $1 \mathrm{~h}$, and then were exposed to $200 \mathrm{ng} / \mathrm{ml}$ of CX3CL1. The ability of the DU145 cells to cross the basement membrane matrix was determined by Transwell migration assay (A) and invasion assay (B). " $\mathrm{p}<0.01$ vs. DMSO. ${ }^{*} \mathrm{p}<0.01 \mathrm{vs.} \mathrm{scrambled-}$ siRNA. Data are presented as the means $\pm \mathrm{SD}$ of three independent experiments.

Tumor necrosis factor- $\alpha$ converting enzyme (TACE or ADAM17) has been found to be a metalloprotease that cleaves membrane-bound TGF- $\alpha$, resulting in release of TGF- $\alpha$ ectodomains and transactivation of EGFR (24). Our previous study reported that TACE/ADAM17 activity is essential for TGF- $\alpha$ maturation in prostate cancer cells. DU145 cells were transfected with specific siRNA for ADAM17 (verified in our previous studies) or Scrambled-siRNA, prior to treatment with CX3CL1. ELISA analysis revealed that the content of soluble TGF- $\alpha$ in culture supernatants was markedly decreased in the hypoxic DU145 cells pre-transfected with ADAM17-siRNA, but not Scrambled-siRNA (Fig. 5E and F), which suggest that downregulation of ADAM17 attenuated CX3CL1-induced increase in TGF- $\alpha$ activity. These results indicate that ADAM17 is responsible for CX3CL1-induced TGF- $\alpha$ secretion.

To verify the role of TACE/TGF- $\alpha$ in CX3CL1-induced EGFR activation, DU145 cells were pre-transfected with ADAM17-siRNA or Scrambled-siRNA, followed by treatment with CX3CL1 for $24 \mathrm{~h}$. Western blot analysis showed that CX3CL1-induced p-EGFR expression was inhibited by ADAM17-siRNA pre-transfection. Moreover, exogenous supplement of TGF- $\alpha$ compensated the inhibitory effect of ADAM17 downregulation (Fig. 5G and H). Taken together, these data suggest that TACE/TGF- $\alpha$ was responsible for CX3CL1-induced EGFR activation in hypoxic DU145 cells.

Finally, we investigated the role of TACE/TGF- $\alpha$ in EMT marker protein expression regulated by CX3CL1. Western blot results showed that there was decreased expression of E-cadherin but elevated expression of vimentin in DU145 cells upon CX3CL1 stimulation compared with the control group, whereas either ADAM17-siRNA pre-transfection or Ab-TGF- $\alpha$ pretreatment abrogated the regulatory effect of CX3CL1 on EMT marker protein expression. In addition, exogenous supplement of TGF- $\alpha$ compensated the inhibitory effect of ADAM17 or TGF- $\alpha$ blockade on expression levels of EMT markers regulated by CX3CL1 (Fig. 6). These data demonstrated that the TACE/TGF- $\alpha$ signaling pathway was involved in CX3CL1-induced EMT of DU145 cells. 
A

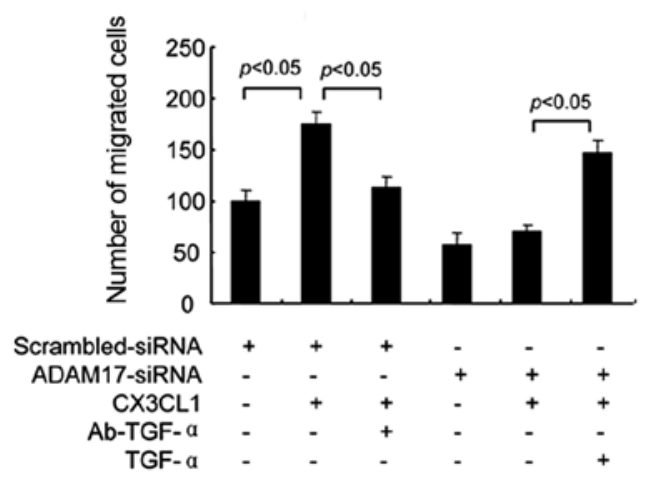

B

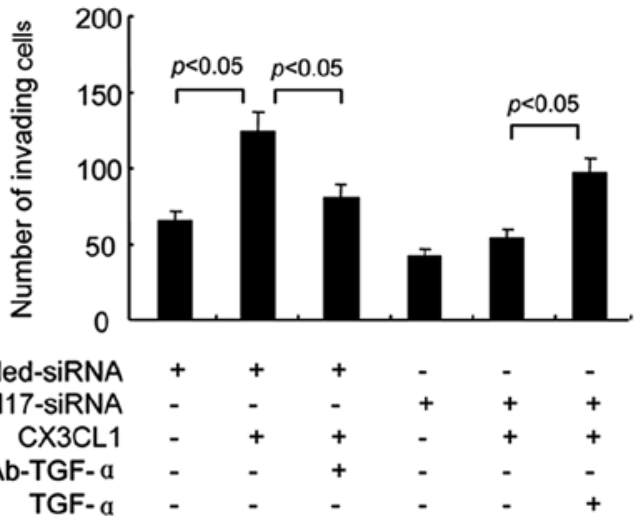

Figure 8. Involvement of the TACE/TGF- $\alpha$ signaling pathway in CX3CL1-induced migration and invasion of DU145 cells. (A) Transwell migration assay. DU145 cells were pre-transfected with ADAM17-siRNA or scrambled-siRNA for $48 \mathrm{~h}$, followed by exposure to $200 \mathrm{ng} / \mathrm{ml}$ of CX3CL1 with or without $50 \mu \mathrm{g} / \mathrm{ml}$ of TGF- $\alpha$ or $10 \mu \mathrm{g} / \mathrm{ml}$ of Ab-TGF- $\alpha$ pretreatment under hypoxic conditions. (B) Transwell invasion assay. These experiments were done triplicate.

CX3CL1-mediated TACE/TGF- $\alpha / E G F R$ signaling pathway contributes to migration and invasion of DU145 cells. Firstly, to investigate the role of EGFR and Slug in the enhancement of migration and invasive abilities of DU145 cells induced by CX3CL1, Matrigel invasion and migration assays were carried out in DU145 cells after treatment with CX3CL1 alone or combined with pretreatment with AG1478 or Slug-siRNA transfection. As shown in Fig. 7, CX3CL1 treatment markedly enhanced the abilities of DU145 cells to cross the basement membrane matrix. Moreover, inhibition of either EGFR or Slug significantly repressed the migration and invasive abilities of the CX3CL1-treated DU145 cells, indicating that the EGFR-dependent Slug pathway was involved in CX3CL1-induced migration and invasion of DU145 cells. Subsequently, we determined the role of TACE/TGF- $\alpha$ in cell migration and invasion induced by CX3CL1. Consistent with the alterations of EMT mentioned above, Matrigel invasion and migration assays demonstrated that CX3CL1 treatment alone increased cell migration and invasion, whereas either ADAM17-siRNA pre-transfection or Ab-TGF- $\alpha$ pretreatment abrogated the regulatory effects of CX3CL1 on cell migration and invasion. Meanwhile, exogenous supplement of TGF- $\alpha$ compensated the inhibitory effect of ADAM17 downregulation (Fig. 8). These results suggest that TACE/GF- $\alpha$ was essential for the regulatory effects of CX3CL1 on cell migration and invasion.

\section{Discussion}

Epithelial-to-mesenchymal transition (EMT), first described by developmental biologists, is a critical process during embryonic development and organogenesis $(2-6,8,10,12-14,17-25)$. Recently, EMT is increasingly considered to play a vital role in tumor invasion and metastasis, and is closely correlated with tumor recurrence. Accumulating evidence indicates that EMT could drive many phenotypic and functional alterations that endow tumor cells with the ability to mobilize via a complex signaling pathway (26). Therefore, regulation of EMT could be an effective strategy to control cancer progression.
CX3CL1, the only member recognized so far that belongs to the $\mathrm{CX} 3 \mathrm{C}$ chemokine subfamily, was reported to participate in the molecular events that regulate cell adhesion, migration and survival of human prostate cancer cells (27). In addition, CX3CL1-CX3CR1 binding was also found to play a crucial role in prostate cancer progression and skeletal metastasis (17). However, whether CX3CL1 exerts its function by initiating the EMT process in prostate cancer remains unknown. In the present study, we found that CX3CL1 induced migration and invasion of androgen-independent prostate cancer cells under hypoxic condition in vitro. We hypothesized that CX3CL1-induced migration and invasion of prostate cancer cells resulted from EMT initiation. Our results showed that under hypoxic conditions, notably morphological changes of DU145 and PC-3 cells were observed after CX3CL1 stimulation for $48 \mathrm{~h}$. Most untreated cells exhibited classical round with tight junctions, and polygon cobblestone-like with typical epithelial cell morphology. However, upon CX3CL1 stimulation, most treated cells became spindle-like with loose connections instead of epithelial-like with tight connections, which morphologically indicated that CX3CL1 induced EMT in DU145 and PC-3 cells. Subsequently, we detected changes in the expression levels of EMT marker proteins in the DU145 and PC-3 cells to further verify whether these morphological changes resulted from functional alterations. Our results revealed that CX3CL1 reduced the expression of epithelial cell marker, E-cadherin, whereas expression of mesenchymal cell marker, vimentin, was significantly elevated. These results imply that CX3CL1 induced an EMT-like phenotype in androgen-independent prostate cancer cells.

EMT is a complicated pathological process, involving complex network regulation. A variety of molecules regulate EMT. The epidermal growth factor receptor (EGFR) family belongs to the tyrosine kinase receptor family, which is widely involved in many physiological or pathological processes such as cell proliferation and differentiation, embryonic development, apoptosis and metastasis $(28,29)$. Our study provides initial evidence that CX3CL1 exposure resulted in EGFR transactivation and subsequent Slug expression, which led to 
the EMT process. G protein-coupled receptor (GPCR) is an important cell membrane receptor, which could be activated by a variety of extracellular physical and chemical stimuli, such as neurotransmitters, chemokines, hormones and drugs. These signals play vital roles in regulating cellular functions (30). Currently, it is generally accepted that EGFRs act as an important conduit for multiple GPCR-related stimuli. Evidence suggests that the EGFR and GPCR pathways usually overlap and interact in cell growth and tissue remodeling (31). CX3CR is the highly selectively chemokine receptor for CX3CL1, belonging to the GPCR family. Commonly, CX3CL1 exerts its functions though binding with its receptor CX3CR1. Thus, we speculated that $\mathrm{CX} 3 \mathrm{CL} 1 / \mathrm{CX} 3 \mathrm{CR} 1$ binding activates EGFR and its downstream signaling pathway.

The matrix metalloprotease (MMP or ADAM) family are surface membrane-associated proteins responsible for the cleavage of several membrane proteins such as TGF- $\alpha$, one of the ligands for the EGFR (32). This biological cell process is called ectodomain shedding. TACE/ADAM17, one of the ADAM family members, is upregulated in several types of cancers and correlates with tumor aggressiveness. The crosstalk between TACE/ADAM17 and EGFR regulates cell proliferation, migration and invasion and survival (30). In the present study, we evaluated the requirement for TACE-dependent EGFR ligand shedding for CX3CL-1 induced EGFR transactivation and EMT. Our results showed that CX3CL1 significantly increased the concentration of soluble TGF- $\alpha$ in culture medium, suggesting that CX3CL1 resulted in release of TGF- $\alpha$ ectodomains. In addition, inhibition of TGF- $\alpha$ or downregulation of ADAM17 depressed CX3CL1-induced EGFR transactivation. Our data demonstrated that TACE/TGF- $\alpha$ was responsible for CX3CL1-induced EGFR activation in hypoxic DU145 cells. Meanwhile, our results showed that the TACE/TGF- $\alpha$ signaling pathway was also responsible for CX3CL1-induced EMT-related gene expression, such as E-cadherin and vimentin. As expected, final Matrigel invasion and migration assays demonstrated that TACE/TGF- $\alpha$ were essential for the regulatory effects of CX3CL1 on cell migration and invasion.

In conclusion, $\mathrm{CX} 3 \mathrm{CL} 1 / \mathrm{CX} 3 \mathrm{CR} 1$ induces EMT and migration and invasion of androgen-independent prostate cancer cells through TACE/TGF- $\alpha /$ EGFR pathway activation. These findings revealed that CX3CL1 may serve as a new target by which to treat prostate cancer.

\section{Acknowledgements}

The present study was supported by grants from the National Natural Science Foundation of China (no. 30973010), the Research Foundation of the Department of Health of Heilongjiang Province (2012-669) and the Startup Fund of The Affiliated Third Hospital of Harbin Medical University (JJ2011-12).

\section{References}

1. Siegel R, Ma J, Zou Z and Jemal A: Cancer statistics, 2014. CA Cancer J Clin 64: 9-29, 2014.

2. Gittes RF: Carcinoma of the prostate. N Engl J Med 324: 236-245, 1991
3. Tannock IF, de Wit R, Berry WR, Horti J, Pluzanska A, Chi KN, Oudard S, Théodore C, James ND, Turesson I, et al; TAX 327 Investigators: Docetaxel plus prednisone or mitoxantrone plus prednisone for advanced prostate cancer. N Engl J Med 351: 1502-1512, 2004

4. Sulzmaier FJ and Ramos JW: RSK isoforms in cancer cell invasion and metastasis. Cancer Res 73: 6099-6105, 2013.

5. Thiery JP, Acloque H, Huang RY and Nieto MA: Epithelial-mesenchymal transitions in development and disease. Cell 139: 871-890, 2009.

6. Liu YN, Yin JJ, Abou-Kheir W, Hynes PG, Casey OM, Fang L, Yi M, Stephens RM, Seng V, Sheppard-Tillman H, et al: miR-1 and miR-200 inhibit EMT via Slug-dependent and tumorigenesis via Slug-independent mechanisms. Oncogene 32: 296-306, 2013.

7. Hotz B, Arndt M, Dullat S, Bhargava S, Buhr HJ and Hotz HG: Epithelial to mesenchymal transition: Expression of the regulators snail, slug, and twist in pancreatic cancer. Clin Cancer Res 13: 4769-4776, 2007.

8. Ding G, Feng C, Jiang H, Ding Q, Zhang L, Na R, Xu H and Liu J: Combination of rapamycin, CI-1040, and 17-AAG inhibits metastatic capacity of prostate cancer via Slug inhibition. PLoS One 8: e77400, 2013.

9. Kwok WK, Ling MT, Lee TW, Lau TC, Zhou C, Zhang X, Chua CW, Chan KW, Chan FL, Glackin C, et al: Up-regulation of TWIST in prostate cancer and its implication as a therapeutic target. Cancer Res 65: 5153-5162, 2005.

10. Whiteland H, Spencer-Harty S, Thomas DH, Davies C, Morgan C, Kynaston H, Bose P, Fenn N, Lewis PD, Bodger O, et al: Putative prognostic epithelial-to-mesenchymal transition biomarkers for aggressive prostate cancer. Exp Mol Pathol 95: 220-226, 2013.

11. Umbas R, Isaacs WB, Bringuier PP, Schaafsma HE, Karthaus HF, Oosterhof GO, Debruyne FM and Schalken JA: Decreased E-cadherin expression is associated with poor prognosis in patients with prostate cancer. Cancer Res 54: 3929-3933, 1994.

12. Bertran E, Crosas-Molist E, Sancho P, Caja L, Lopez-Luque J, Navarro E, Egea G, Lastra R, Serrano T, Ramos E, et al: Overactivation of the TGF- $\beta$ pathway confers a mesenchymal-like phenotype and CXCR4-dependent migratory properties to liver tumor cells. Hepatology 58: 2032-2044, 2013.

13. Izumi K, Fang LY, Mizokami A, Namiki M, Li L, Lin WJ and Chang C: Targeting the androgen receptor with siRNA promotes prostate cancer metastasis through enhanced macrophage recruitment via CCL2/CCR2-induced STAT3 activation. EMBO Mol Med 5: 1383-1401, 2013.

14. Blum DL, Koyama T, M'Koma AE, Iturregui JM, MartinezFerrer M, Uwamariya C, Smith JA Jr, Clark PE and Bhowmick NA: Chemokine markers predict biochemical recurrence of prostate cancer following prostatectomy. Clin Cancer Res 14: 7790-7797, 2008.

15. Xu X, Wang Y, Chen J, Ma H, Shao Z, Chen H and Jin G: High expression of CX3CL1/CX3CR1 axis predicts a poor prognosis of pancreatic ductal adenocarcinoma. J Gastrointest Surg 16: 1493-1498, 2012

16. Gaudin F, Nasreddine S, Donnadieu AC,Emilie D, Combadière C, Prévot S, Machelon V and Balabanian K: Identification of the chemokine CX3CL1 as a new regulator of malignant cell proliferation in epithelial ovarian cancer. PLoS One 6: e21546, 2011.

17. Jamieson WL, Shimizu S, D'Ambrosio JA, Meucci O and Fatatis A: CX3CR1 is expressed by prostate epithelial cells and androgens regulate the levels of CX3CL1/fractalkine in the bone marrow: Potential role in prostate cancer bone tropism. Cancer Res 68: 1715-1722, 2008.

18. Xiao LJ, Chen YY, Lin P, Zou HF, Lin F, Zhao LN, Li D, Guo L, Tang JB, Zheng XL, et al: Hypoxia increases CX3CR1 expression via HIF-1 and NF- $\mathrm{KB}$ in androgen-independent prostate cancer cells. Int J Oncol 41: 1827-1836, 2012.

19. Yuan WC, Lee YR, Huang SF, Lin YM, Chen TY, Chung HC, Tsai CH, Chen HY, Chiang CT, Lai CK, et al: A cullin3-KLHL20 ubiquitin ligase-dependent pathway targets PML to potentiate HIF-1 signaling and prostate cancer progression. Cancer Cell 20: 214-228, 2011.

20. Philip B, Ito K, Moreno-Sánchez R and Ralph SJ: HIF expression and the role of hypoxic microenvironments within primary tumours as protective sites driving cancer stem cell renewal and metastatic progression. Carcinogenesis 34: 1699-1707, 2013.

21. Traish AM and Morgentaler A: Epidermal growth factor receptor expression escapes androgen regulation in prostate cancer: A potential molecular switch for tumour growth. Br J Cancer 101: 1949-1956, 2009. 
22. Antonarakis ES, Carducci MA and Eisenberger MA: Novel targeted therapeutics for metastatic castration-resistant prostate cancer. Cancer Lett 291: 1-13, 2010.

23. Lo HW, Hsu SC, Xia W, Cao X, Shih JY, Wei Y, Abbruzzese JL, Hortobagyi GN and Hung MC: Epidermal growth factor receptor cooperates with signal transducer and activator of transcription 3 to induce epithelial-mesenchymal transition in cancer cells via up-regulation of TWIST gene expression. Cancer Res 67: 9066-9076, 2007.

24. Maretzky T, McIlwain DR, Issuree PD, Li X, Malapeira J, Amin S, Lang PA, Mak TW and Blobel CP: iRhom2 controls the substrate selectivity of stimulated ADAM17-dependent ectodomain shedding. Proc Natl Acad Sci USA 110: 11433-11438, 2013.

25. Floor S, van Staveren WC, Larsimont D, Dumont JE and Maenhaut C: Cancer cells in epithelial-to-mesenchymal transition and tumor-propagating-cancer stem cells: Distinct, overlapping or same populations. Oncogene 30: 4609-4621, 2011.

26. Tomaskovic-Crook E, Thompson EW and Thiery JP: Epithelial to mesenchymal transition and breast cancer. Breast Cancer Res 11: 213, 2009.
27. Shulby SA, Dolloff NG, Stearns ME, Meucci O and Fatatis A: CX3CR1-fractalkine expression regulates cellular mechanisms involved in adhesion, migration, and survival of human prostate cancer cells. Cancer Res 64: 4693-4698, 2004.

28. DeHaan AM, Wolters NM, Keller ET and Ignatoski KM: EGFR ligand switch in late stage prostate cancer contributes to changes in cell signaling and bone remodeling. Prostate 69: 528-537, 2009.

29. Shah RB, Ghosh D and Elder JT: Epidermal growth factor receptor (ErbB1) expression in prostate cancer progression: Correlation with androgen independence. Prostate 66: 1437-1444, 2006.

30. Kenny PA: TACE: A new target in epidermal growth factor receptor dependent tumors. Differentiation 75: 800-808, 2007.

31. Gschwind A, Hart S, Fischer OM and Ullrich A: TACE cleavage of proamphiregulin regulates GPCR-induced proliferation and motility of cancer cells. EMBO J 22: 2411-2421, 2003.

32. Harris RC, Chung E and Coffey RJ: EGF receptor ligands. Exp Cell Res 284: 2-13, 2003. 